\title{
Letter to "Prospective analysis of transvaginal mesh hysteropexy in the treatment of uterine prolapse"
}

\author{
Suna Yıldırım Karaca ${ }^{1,2}$
}

Received: 18 August 2021 / Accepted: 31 August 2021 / Published online: 3 November 2021

(c) The International Urogynecological Association 2021

\section{Dear Editor,}

I read with great interest the recently published article on the efficiency of transvaginal mesh hysteropexy operation for uterine prolapse [1]. There are, however, several potential issues with the article, with implications for the reliability of the findings. These problems include misclassification of patients in the preoperative Pelvic Organ Prolapse Quantification System (POP-Q), and questioning the indications for surgery in non-advanced uterine prolapse.

First of all, the authors reported the median value of the D point as +2 with the POP-Q classification of the patients in the preoperative period. In addition, the preoperative minimum and maximum D-point values of these patients were between -3 and +11 . Statistically, when min-max and median values are taken into account (even if we do not include patients with a $\mathrm{D}$ score of +1 ), it shows that more than half of the patients have stage 4 uterine prolapse [2]. However, in the results of the article, the authors reported that $40 \%(16 / 40)$ of the patients had stage 4 prolapse before surgery.

Another conflicting situation regarding the POP-Q classification is related to the postoperative $\mathrm{C}$ point. The authors reported the minimum value of the preoperative $\mathrm{C}$ point as -1 in the article. The minimum value of the $\mathrm{C}$ point after the operation was recorded as 0 . This situation creates the prejudice that hysteropexy surgery performed in at least one patient worsened the POPQ classification of the $\mathrm{C}$ point.

Secondly, with the indication of stage 3 and stage 4 uterine prolapse, the decision to surgery is an appropriate treatment model. However, we wondered why the authors needed

Suna Yıldırım Karaca

drsunayildirimkaraca@gmail.com

1 Department of Obstetrics and Gynaecology, Health Sciences University Tepecik Education and Research Hospital, Izmir, Turkey

2 Department of Stemcell, Ege University, Institute of Health Sciences, Izmir, Turkey a transvaginal mesh hysteropexy operation in stage 2 uterine prolapse patients $(32.5 \%, 13 / 40)$.

Finally, the authors compared the preoperative and postoperative results of quality of life scales and found that transvaginal mesh hysteropexy provided significant improvement in quality of life. We congratulate the authors for this aspect. However, we would like to emphasize that the effects of the concomitant single-incision midurethral sling and anal sphincteroplasty procedures on the quality of life are important [3]. Therefore, it is important to explain this situation as the limitation of the study.

\section{Declarations}

Conflicts of interest The author reports no conflict of interest

\section{References}

1. Khandwala S, Cruff J. Prospective analysis of transvaginal mesh hysteropexy in the treatment of uterine prolapse. Int Urogynecol J. 2021;32(8):2241-7.

2. Freidlin B, Gastwirth JL. Should the Median Test be Retired from General Use? Am Stat. 2000;54(3):161-4.

3. Mattsson NK, Karjalainen PK, Tolppanen AM, Heikkinen AM, Sintonen H, Härkki P, Nieminen K, Jalkanen J. Pelvic organ prolapse surgery and quality of life-a nationwide cohort study. Am J Obstet Gynecol. 2020;222(6):588.e1-588.e10.

Publisher's note Springer Nature remains neutral with regard to jurisdictional claims in published maps and institutional affiliations. 